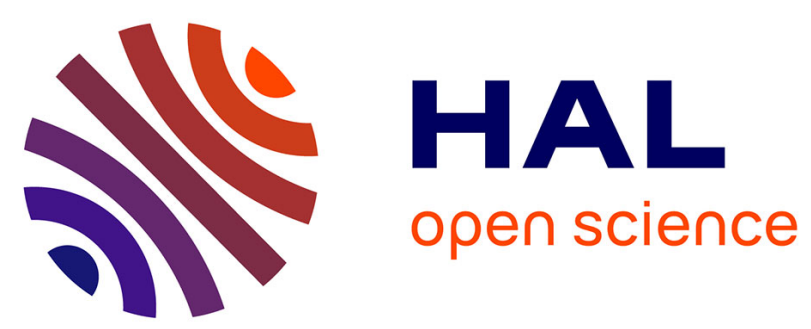

\title{
SATURNE LATEST RESULTS FOR POLARIZED BEAMS
}

P. Chamouard, J. Lagniel, J. Lemaire, A. Tkatchenko, J. Yonnet

\section{To cite this version:}

P. Chamouard, J. Lagniel, J. Lemaire, A. Tkatchenko, J. Yonnet. SATURNE LATEST RESULTS FOR POLARIZED BEAMS. Journal de Physique Colloques, 1990, 51 (C6), pp.C6-569-C6-572. 10.1051/jphyscol:1990675 . jpa-00230945

\section{HAL Id: jpa-00230945 https://hal.science/jpa-00230945}

Submitted on 1 Jan 1990

HAL is a multi-disciplinary open access archive for the deposit and dissemination of scientific research documents, whether they are published or not. The documents may come from teaching and research institutions in France or abroad, or from public or private research centers.
L'archive ouverte pluridisciplinaire HAL, est destinée au dépôt et à la diffusion de documents scientifiques de niveau recherche, publiés ou non, émanant des établissements d'enseignement et de recherche français ou étrangers, des laboratoires publics ou privés. 


\section{SATURNE LATEST RESULTS FOR POLARIZED BEAMS}

P.A. CHAMOUARD, J.M. LAGNIEL, J.L. LEMAIRE, A. TKATCHENKO and J. YONNET

Laboratoire National SATURNE, CEA-DSM et CNRS-IN2P3, SaClay, F-91191 Gif sur Yvette, France

Résumé - Les intensités en protons et en deutons ont pu être progressivement portées à $\overline{2.10^{11}}$ particules/cycle depuis la mise en service de MIMAs en 1987 et gráce aux améliorations faites sur la source. Il $n^{\prime} y$ a pas de résonance de dépolarisation en deutons. Les résonances de dépolarisation en protons dans MIMAS et SATURNE ont fait 1 'objet d'études systématiques jusqu'à 1 'énergie maximale de SATURNE (2.91 GeV). Compte tenu des améliorations encore possibles sur 1 a spurce et moyennant une injection à énergie plus élevée dans MIMAS une intensité de $5 \cdot 10^{11} \mathrm{p}$ ou d par cycle est possible.

Abstract - The intensities for polarized protons or deuterons have been reached up to $2.10^{11} \mathrm{p}$ or $d$ by cycle since MIMAS operation in 1987 and also with the last improvements of the source. There is no depolarization for deuterons but for protons all the depolarizations in MIMAS and SATURNE have been studied up to the maximum energy. With the possible improvements on the source, associated to an higher injection energy into MIMAS, intensities up to $5.10^{1} \mathrm{p}$ or d are possible.

\section{1 - INTRODUCT ION}

The SATURNE II complex for polarized beams is constituted by a $400 \mathrm{kV}$ DC preinjector housing the polarized source. The booster-storage ring MIMAS and ring SATURNE II. One polarimeter is set after the preinjector and dedicated to the polarization control of deuterons. The other polarimeter is placed after the first SATURNE's extraction channel.

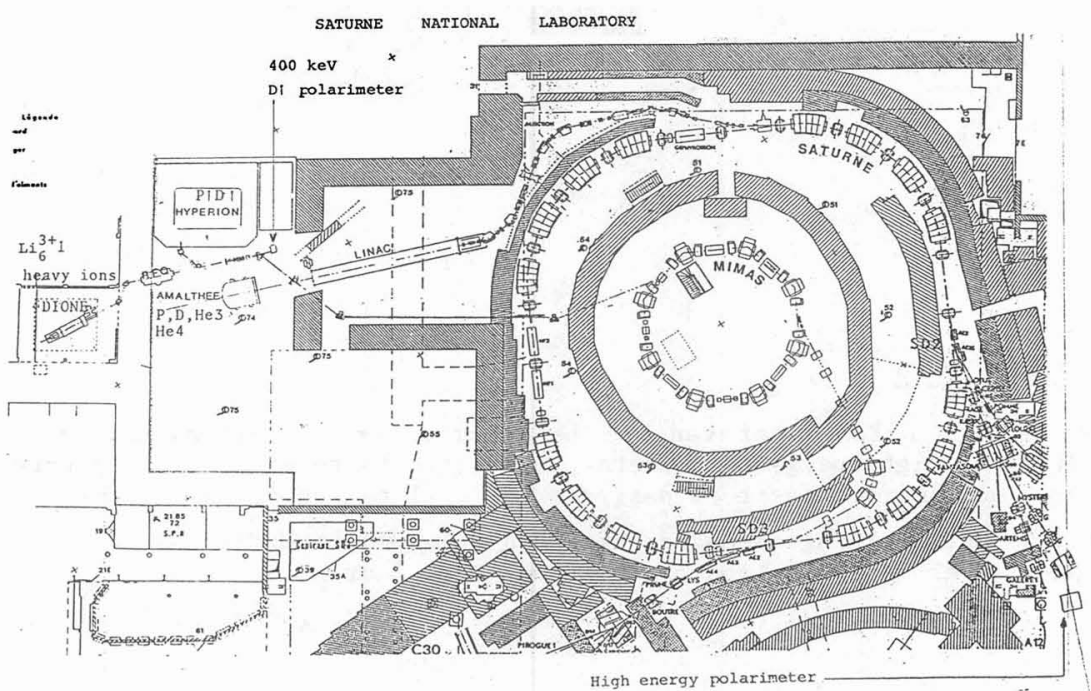




\section{2 - THE POLARIZED SOURCE "HYPERION"}

This source built in 1981 began to operate in 1982. The high voltage terminal houses :

- a) the ground state atomic source : RF dissociator $f=17 \mathrm{MHz}$, the tapered sextupole and removable RF transitions ( 2 for protons, 3 for deuterons), the nozzle made of gold covered copper is cooled at $80 \mathrm{~K}$. The atomic source operates in the pulsed mode (both the pressure and RF),

- b) the electron beam reflex ionizer built by ANAC has been deeply modified mainly on the following points :

- a very fine alignment between the mechanical axis of the electrostatic electrodes and the magnetic axis of coils,

- a reliable electron gun equipped with alumina insulators, tantalum and molybdenum electrodes allowing to operate at high temperatures without alignment losses,

- the voltage of the electron extraction electrode is pulsed, in these conditions it is possible to operate with higher electron current. The DC mode is only used during out gassing.

- c) the beam is extracted at $17 \mathrm{keV}$, after ionization the polarization is set in the vertical direction by means of an electrostatic mirror followed by a solenoind. Then the beam is accelerated up to $400 \mathrm{keV}$. The standard beam operation is :

- extracted current at $17 \mathrm{keV}: 400-500 \mu \mathrm{A}$

- pulse length $1.5 \mathrm{msec}$ (protons) $1 \mathrm{msec}$ (deuterons)

${ }_{\mathbf{n}} / \pi=3.10^{-6} \mathrm{mrad}(80 \%)$

The current at MIMAS's inflector is $200-250 \mu \mathrm{A}$ giving $2.10^{11} \mathrm{p}$ or d accelerated in MIMAS and SATURNE.

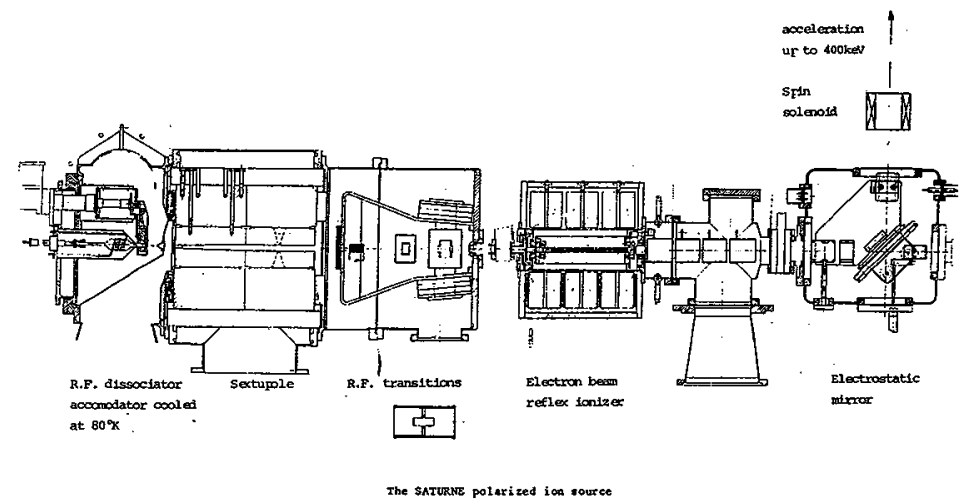

3 - RESULTS OF POLARIZATION

Immediately with MIMAS, a factor of ten has been gotten on the intensify, it has been necessary to modify the high energy polarimeter to be able to receive 2.10 particles. Nevertheless a new polarimeter has been designed and will be set in next january (1).

Deuterons beams : No depolarizing resonance has been observed in MIMAS and SATURNE, and typically the polarization of the beam is $85 \%$ of :

$$
\begin{array}{ll}
\mathrm{Pz}= \pm 2 / 3 & \mathrm{Pzz}=0 \\
\mathrm{Pz}= \pm 1 / 3 & \mathrm{Pzz}= \pm 1
\end{array} \quad \text { intensity } 2.10^{11} \mathrm{~d}
$$


Protons beams : The situation between MIMAS and the other machines is completely different. The energy range of MIMAS is from $400 \mathrm{keV}$ to $47 \mathrm{MeV}$, the beam is not relativistic $\gamma=1$; that means if the operating point is close fo a resonant 1 ine, the beam will remain a long time on the line; the high intensity $\left(2.10^{11} \mathrm{p}\right)$ induces by space charge effect a variation of wave numbers $\left(v_{z}=2.2\right) \Delta v z=0.1$.; To day, MIMAS is the only machine space charge dominated with polarized beams.

The line $V G p=4-v z(v z=2.206)$ is set on the injection point, the association of the space charge effect and synchrotron oscillation during the adiabatic capture and the beginning of acceleration produces multiple crossings of the line, even if this line is weak, the polarization falls down to $65 \%$ (instead of $90 \%$ ), the correction of this line by correction quadrupoles gives only an improvement of $10 \%$. In these conditions the vertical operating point has been modified : $v z=2.48$ close to the half integer allowing a large possible $\Delta \nu z$ without crossing $V G=4-v z$ in these condition a polarization of $90 \%$ with $2.10^{11}$ is possible (all measurements for MIMAS tuning have been made at $250 \mathrm{MeV}$ in SATURNE, see diagram)

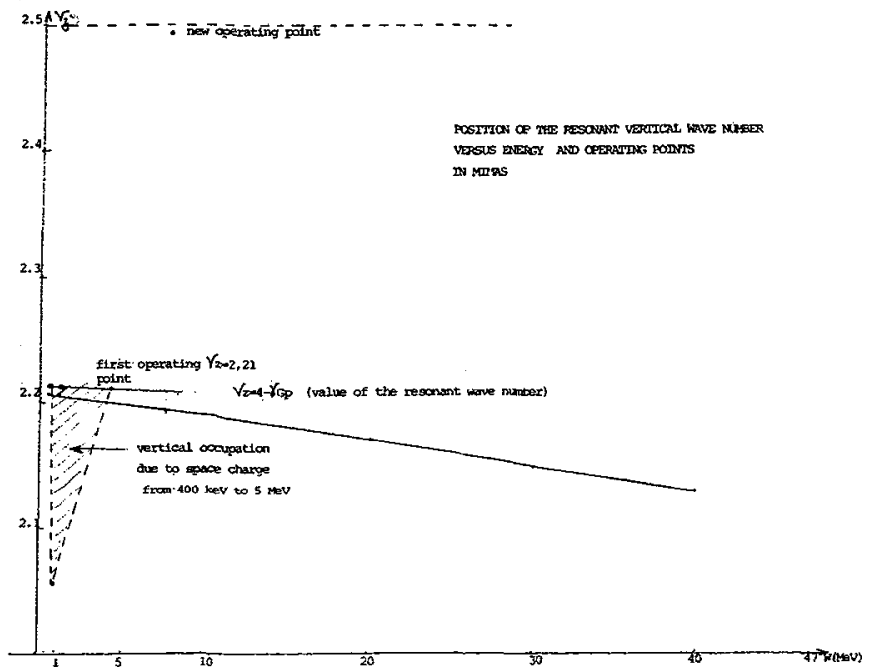

4 - SATURNE TUNING

In SATURNE $\mathrm{d} \gamma / \mathrm{dt}$ allows, the possibility to change the speed of crossing the 1 ines, and the correction are made by 3 ways (2) :

$$
\begin{aligned}
& \text { multi-pulsed dipoles correction } \\
& \text { multi-pulsed multiples corrections }
\end{aligned}
$$

The line $\mathcal{V}_{G}=2$ is corrected (dipoles corrections)

4).

$v_{G}=3,4,5,6,7$ are flipped (the flip is enhanced by dipole correctors for 3 and

The line $\gamma_{G}=\nu z$ and $\gamma_{G}=8-\nu z$ are flipped with $\nu z$ variation. The lines

$\gamma_{G}=N \pm M \nu z$ are crossed with quadrupolar corrections and $v z$ variation, each one has an effect.

The 1 ine $V_{G}=v_{x}$ is corrected by 4 skew quadrupoles.

A very flexible computer control (hard and soft) for the correctors and main quadrupoles is necessary.

Other lines $V_{G}=\mathbb{N} \pm v \mathbf{X} \pm \nu \mathbf{z}$ can be excited during extraction by the main hexapoles inducing the betatron resonance $v x=11 / 3$.

The 1 ines are avoided by vertical tuning $v z$. 
A predictive computer programm gives all the possible lines up to the third order, to assume the best possible tuning of the machine when an energy is needed by the user, this programm shows the 1 ines in the $v x, v z$ diagram for a given energy but also the position of the lines in the diagram $\nu x, r z$ versus $W$. To day, the polarization of the protons beam is $80 \%$ up to $2.91 \mathrm{GeV}$ (maximum $2.95 \mathrm{GeV}$ ) with $2.10^{11} \mathrm{p}$.

\section{5 - POSS IBLE IMP ROVEMENTS}

A test bench has been set in order to study the cooling of the atomic beam in the nozzle, the last results have shown the possibility to reduce the temperature at $35 \mathrm{~K}$ with $\mathrm{N} 2$ injection in the nozzle, is these conditions with a new sextupole an improvement of 1.7 is possible (3).

Using higher voltages on the ionizer allowing larger electron density the extracted current has been reached to $700 \mu \mathrm{A}$; in these condition the total improvement on the ion beam intensity is :

$$
700 / 500 \times 1,7=2.38
$$

corresponding to $1.2 \mathrm{~mA}$ extracted of the ioniser. If the beam is injected at $800 \mathrm{keV}$ allowing the same space charge an dynamic effects on the beam, an intensity of $5.10^{11}$ will be possible.

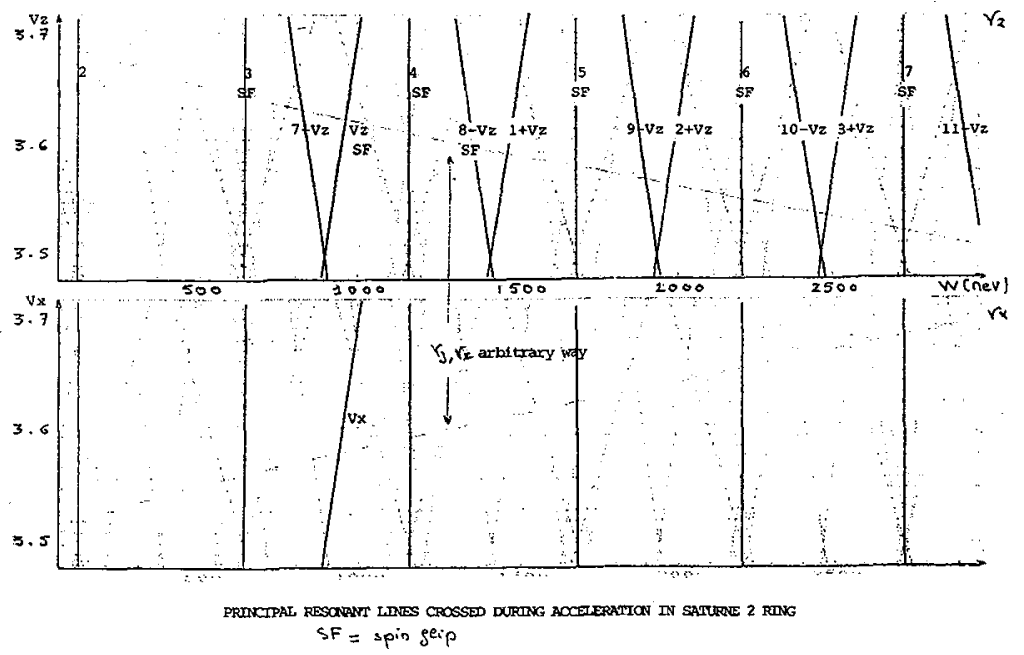

6 - CONCLUSION

To day, SATURNE's polarized beams results show :

- the possibility to get high intensities, probably $10^{12}$ p or a by cycle with reasonable improvements on the source,

the polarization can be conserved at large values ( $80 \%$ ) with a minimum of losses even with many depolarizing lines.

RE FE RE NCE $S$

/1/ Chamouard, PA., Rommel, G., Olivier, M., Tkatchenko, A., Mimas Commissioning EPAC, Rome, 1988

/2/ Laclare, Jl., Accélération de protons polarisés, Journées d'Etudes Saturne 2, Auxois, 1977

13/ Lemaire, JL., Present results on the polarized proton and deuteron source at Saturne, Workshop on the Polarized sources, Tsukuba, 1990. 